Original article

\title{
Sexuality Education During Adolescence and Use of Modern Contraception at First Sexual Intercourse Among Mexican Women
}

\author{
Alyssa R. Hersh ${ }^{\mathrm{a}, *}$, Biani Saavedra-Avendaño, M.Sc. ${ }^{\mathrm{b}}$, Raffaela Schiavon, M.D. ${ }^{\mathrm{c}}$, and \\ Blair G. Darney, Ph.D., M.P.H. ${ }^{\mathrm{a}, \mathrm{d}}$ \\ ${ }^{a}$ Department of Obstetrics and Gynecology, Oregon Health and Science University, Portland, Oregon \\ ${ }^{\mathrm{b}}$ CIDE: Centro de Investigación y Docencia en Economia, Mexico City, Mexico \\ ${ }^{\mathrm{c}}$ Independent Consultant, Mexico City, Mexico \\ ${ }^{\mathrm{d}}$ Center for Population Health Research (CISP), National Institute of Public Health (INSP), Cuernavaca, Mexico
}

Article history: Received January 24, 2019; Accepted May 30, 2019

Keywords: Adolescent; Sexual intercourse; Contraception; Latin America; Mexico; Sexuality education

\section{A B S T R A C T}

Purpose: Mexico has implemented comprehensive sexuality education. We hypothesized that young women who received sexuality education as adolescents would be more likely to report modern contraceptive use at first sexual intercourse.

Methods: We used a nationally representative survey of Mexican women aged 20-24 years who were asked about experiences during adolescence. We defined our treatment variable in three mutually exclusive groups: comprehensive sexuality education (receipt of education in nine topics); incomplete sexuality education (receipt of at least one topic in each of three themes); or no sexuality education. Our outcome was use of modern contraception at first sexual intercourse. We included individual- and household-level sociodemographic factors. All presented data used survey weights. We used multivariable logistic regression and predicted probabilities to estimate the association between sexuality education and using modern contraception at first intercourse.

Results: In our sample ( $\mathrm{n}=2,725$; population $\mathrm{N}=4,008,722$ ), $60.6 \%$ of participants reported receipt of comprehensive, $15.6 \%$ of incomplete, and $23.9 \%$ of no sexuality education; $62.5 \%$ reported utilizing a modern method of contraception at first intercourse. Women who reported receiving comprehensive (adjusted odds ratio: 2.3, 95\% confidence interval [CI]: 1.7, 3.2) or incomplete (adjusted odds ratio: $2.4,95 \% \mathrm{CI}: 1.3,4.2$ ) sexuality education had higher odds of using contraception at first intercourse compared with no sexuality education. The absolute multivariable probabilities of using modern contraception at first intercourse were 57.5\% (95\% CI: 55.2\%-59.8\%), 60.4\% (95\% CI: 56.0\%-64.9\%), and 37.6\% (95\% CI: 33.9\%-41.3\%) among comprehensive, incomplete, and no sexuality education, respectively.

Conclusions: Sexuality education is associated with contraception use at first intercourse among young women in Mexico.

(c) 2019 Society for Adolescent Health and Medicine. All rights reserved.

\section{IMPLICATIONS AND CONTRIBUTION}

Receipt of both comprehensive and incomplete sexuality education is associated with use of a modern contraceptive method at first intercourse in Mexico. These findings should motivate increased support for sexuality education in Mexico and can inform current national efforts to reduce adolescent pregnancy in Mexico.

\footnotetext{
Conflicts of interest: The authors have no conflicts of interest to disclose. Disclaimer: The content is solely the responsibility of the authors and does not necessarily represent the official views of the Agency for Healthcare Research and Quality.

* Address correspondence to: Alyssa R. Hersh, Department of Obstetrics and Gynecology, Oregon Health and Science University, Mail Code L466, 3181 SW Sam Jackson Park Rd., Portland, OR 97202.

E-mail address: hersha@ohsu.edu (A.R. Hersh).
}

The birth rate among adolescent women aged $15-19$ years in Mexico is one of the highest in the world at 68 births per 1,000 [1]. Owing to the consequences of adolescent birth, including reduced educational attainment, earning potential, and socioeconomic status in addition to adverse obstetric outcomes, the Mexican government has prioritized adolescent pregnancy as a 
public health issue [2]. Mexico's National Strategy for the Prevention of Adolescent Pregnancy (ENAPEA) has two goals: to reduce the adolescent fertility rate by $50 \%$ and "eradicate pregnancy among adolescents aged 14 years or younger" by 2030 [3].

Use of contraception among sexually active adolescents varies widely around the world, and literature suggests that behavioral, cultural, social, and health system factors affect contraception use [4-6]. For example, population behavioral changes, such as increased contraception use, are associated with reduced risk of pregnancy in adolescence [7,8]. Although sexuality education has been shown to be effective at reducing adolescent pregnancy, studies that have evaluated the association between sexuality education and contraceptive use have found mixed results [9-13].

There are numerous types of sexuality education. Abstinenceonly sexuality education focuses on pregnancy prevention by avoiding sexual intercourse [13]. Contrarily, comprehensive sexuality education incorporates education about numerous topics, including human development, relationships, sexual and reproductive health and behavior, and culture, seeking to empower students to develop skills and attitudes for healthy relationships [14]. Several studies have examined the association of each type of sexuality education with contraception use at first intercourse [10-13]. However, there are no data establishing a causal relationship.

Sexuality education is a national policy in Mexico and must be integrated into both public and private schools beginning from primary school [15]. In 2015, Mexico's National Strategy for the Prevention of Adolescent Pregnancy (ENAPEA) directed the development of an evidence-based comprehensive sexuality education encompassing biological, psychological, social, economic and cultural topics [3]. However, despite the national curriculum in comprehensive sexuality education, students receive varying amounts of sexuality education and most do not receive education in all recommended topics [16].

In alignment with the Mexican government's focus on adolescent pregnancy prevention and a national sexuality education curriculum, we sought to assess the association of sexuality education with contraceptive use at first sexual intercourse. We hypothesized that there is a positive association between receipt of comprehensive or incomplete sexuality education, as determined by the number of topics covered at school and use of a modern method of contraception, including implants, intrauterine devices, injection, pills, patch, condoms, spermicides, or emergency contraceptive pills, at first sexual intercourse among young Mexican women.

\section{Methods}

\section{Study design and population}

We conducted a cross-sectional study using data from the 2017 National Survey of Factors and Determinants of Adolescent Pregnancy (ENFaDEA; Encuesta Nacional de los Factores Determinantes del Embarazo Adolescente) [17]. ENFaDEA surveyed women aged 20-24 years about their current reproductive health and sociodemographic information as well as information about their households and themselves during adolescence. ENFaDEA was fielded by the School of Social Work (ENTS; Escuela Nacional de Trabajo Social) at the National Autonomous University of Mexico (Spanish acronym: UNAM). The data are publicly available [17]. The survey data were collected through face-to-face interviews similar to the methodology used for Mexico's large population-based surveys as well as other surveys fielded by the same technical group [18,19]. A total of 24,093 households and 3,380 individual young women were surveyed, with a response rate of $81.5 \%$ at the household and $91.4 \%$ at the individual levels.

The study was designed to be nationally representative of both rural and urban participants, meaning participants were sampled to ensure adequate representation of both rural and urban areas and permit inference to the national population. It was estimated that 15,000 urban households and 15,000 rural households would have to be visited to survey 3,400 women aged 20-24 years. Following standard definitions used by the Mexican government, rural was defined as $<2500$ inhabitants. Sixty urban municipalities were selected, factoring in the population size; all urban municipalities with more than 800,000 residents were included in the study, and the remainder were selected with probabilities proportional to their population size. For each sample municipality, a list of houses was compiled, from which a random sample of 10 houses was obtained. For rural municipalities, urban municipalities were excluded, and 20 municipalities were selected with probabilities proportional to their population size. In this case, 10 municipalities were selected randomly, and a random sample of 75 houses was obtained. In both urban and rural settings, study personnel visited each selected household. The household survey was completed with a member of each household, and if there were women aged 20-24 years in the household, each completed the individual questionnaire. Questionnaires were entered into STATA and deidentified.

Our analytic sample includes participants who reported sexual intercourse at least once, had attended at least some school, and had complete data for the sexuality education and contraception use questions ( $\mathrm{n}=2,725$; population $\mathrm{N}=4,008,722$; Figure 1). Our use of the deidentified data for secondary analysis was deemed not human subjects research by the Institutional Review Board at Oregon Health \& Science University.

\section{Measures}

Our independent variable was receipt of sexuality education with three mutually exclusive categories. Participants were asked whether a professor or professional at school had discussed nine different sexual and reproductive health topics and was intended to capture formal sexuality education (Figure 2); the survey did not differentiate between formal and informal sexuality education. However, we considered this sexuality education because of the implementation of Mexico's national comprehensive sexuality education policy. Participants were considered to have received comprehensive sexuality education if all nine topics were discussed. Among those who did not receive education on all nine topics, participants were considered to have received incomplete sexuality education if they had received education on at least one topic in each of three themes; we used a previously published framework to determine the themes and which topics fit into which theme [16]. The three themes were reproductive health, self-efficacy, and rights and relationships.

Our outcome was use of a modern contraceptive method during or immediately after first sexual intercourse. Participants were asked, "in your first sexual relations, what did you or your partner do or use to prevent pregnancy or a sexually transmitted infection?" Then, the interviewer was instructed to circle any method reported by the participant. Modern methods included 


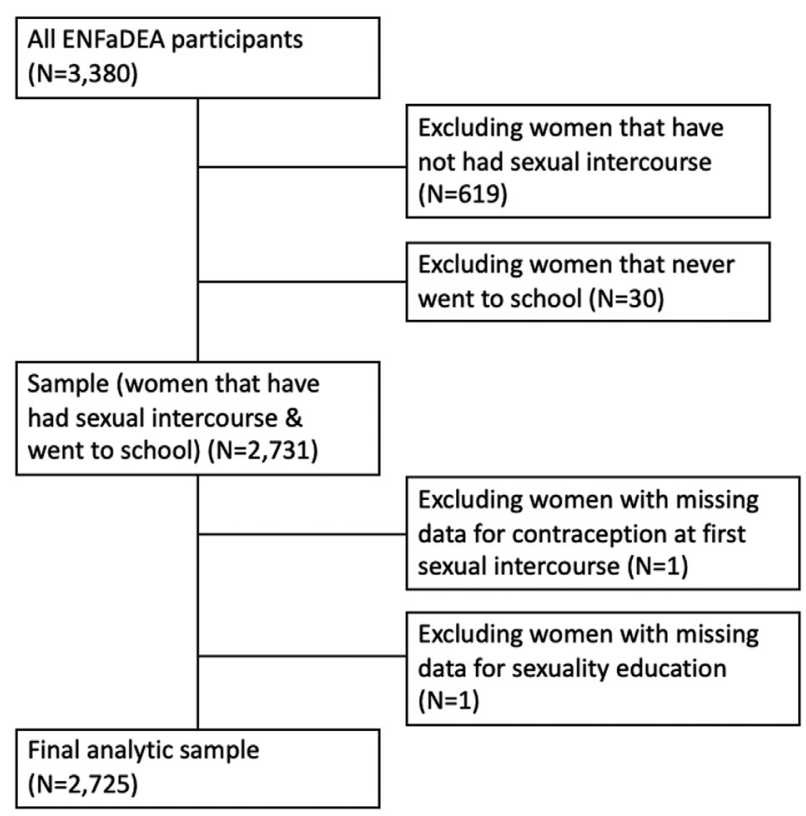

Figure 1. Analytic sample. ENFaDEA = National Survey of the Determinant Factors of Adolescent Pregnancy.

implants, intrauterine devices, injection, pills, patch, condoms, spermicides, and emergency contraceptive pills; participants who reported no method or reported using withdrawal or fertility awareness methods were classified as not using a modern method [20].

We included demographic information, religion, and social factors of participants in our study. Questions asked about the participant were framed to assess personal and familial characteristics at the time of the survey or at fifteen years of age (a proxy for during adolescence). Current self-identified indigenous status was classified as a binary variable, using the question, "do you consider yourself indigenous according to your traditions or customs?" Age at first sexual intercourse was divided into three categories: younger than age 16, ages 16-19, or 20 years or older.

Among the variables assessing the participant at the age of 15 years was location of residence, which was categorized as urban versus rural. Participants were asked about household structures and appliances at age 15 , from which we calculated a wealth index using principle component analysis [21]. We then created a variable that categorized participants into tertiles, representing wealthy, middle-income, and poor households. We also included a binary indicator of health insurance status at age 15. The survey asked about religion during adolescence, but as the large majority of individuals were Catholic, we chose to use the participants' level of religiousness during adolescence instead, with a description of religiousness that included "not religious," "a little religious," "religious," and "very religious." We categorized religiousness into "not religious," which included the two least religious categories, "somewhat religious," and "very religious." This was not a validated method of measuring religiousness; however, prior literature has demonstrated large variability in beliefs within religious affiliations and behaviors are more closely associated with beliefs than the religious affiliation itself [22-24].
We assessed information about the participant's family: educational attainment of the participant's mother (secondary school completion) and whether the participant's mother experienced an adolescent pregnancy (pregnancy before age 20). We also included whether "someone" at home discussed sexual and reproductive health topics during adolescence (five topics: menstruation, pregnancy, relationships, sex, and contraception), which could have been any household member.

\section{Statistical analysis}

Table 1 shows crude and weighted proportions. All other analyses present only the weighted results. We used survey weights for all analyses to account for complex sampling design and produce national estimates. The survey weights were designed to allow inference to the national rural and urban populations of Mexico. We used Pearson chi-squared test or two sample t-tests, as appropriate, for the analysis of differences among participants who had received comprehensive sexuality education, incomplete sexuality education, and no sexuality education. We used bivariate statistics to assess the relationship between receipt of sexuality education and use of modern contraception at first sexual intercourse.

We next developed a multivariable logistic regression model to assess the association between comprehensive and incomplete sexuality education, compared with no sexuality education and modern contraception use at first sexual intercourse. Model building was an iterative process. We first relied on previous literature to identify variables for inclusion in our models $[10,12,25]$. We next assessed the correlation among variables; many were highly correlated. We selected variables that were included in previous analyses on this topic or were different by receipt of sex education and were not collinear with other variables. We hypothesized a priori that sexuality education topics discussed at home might modify the relationship between sex and modern contraception use. We tested this interaction; it was nonsignificant, and we chose not to include it in the final model as it was highly correlated with other variables including wealth and location of residence. In addition, we used Bayesian information criteria to compare potential models. Our final model included rural residence, religiousness, the wealth index, age at first sexual intercourse, and health insurance in addition to our independent variable.

To ease interpretation, we calculated the multivariable absolute and relative predicted probabilities of using modern contraception at first sexual intercourse based on receipt of sexuality education, holding the covariates included in the regression model at the mean [26].

\section{Sensitivity analysis}

We performed several sensitivity analyses comparing results from models with different categorization for a variety of variables to evaluate if these changes affected estimates of the relationship between sexuality education and use of contraception at first intercourse. Results were robust to model specification. We evaluated a binary variable for age at first sexual intercourse, as $<20$ or $\geq 20$ years of age, to test whether changing our definition of age at first sex changed the observed relationship between contraception use at first sexual intercourse. In addition, we created quintiles for household wealth to determine if changes to the categorizations affected the association. We also 


\section{PERCENTAGE OF PARTICIPANTS REPORTING THAT THEY DISCUSSED EACH TOPIC AT SCHOOL}

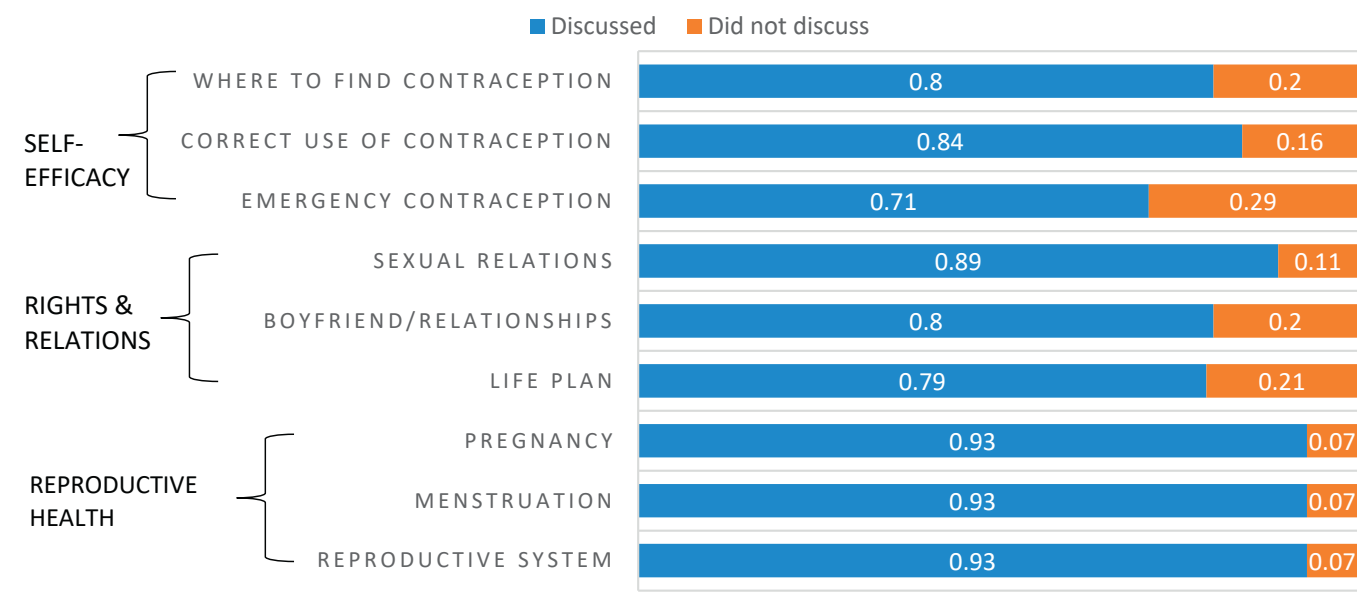

Figure 2. Proportion of participants reporting they received education in each topic at school.

tested the association by defining incomplete sexuality education as only receiving the reproductive health topics, which were covered in sexuality education in the past before the adoption of comprehensive sexuality education in Mexico. Finally, we tested the association with comprehensive and incomplete sexuality education in separate models and also as a direct comparison to each other (excluding the no sexuality education group). Our results were robust to all these sensitivity analyses; we present only our final model. We used STATA 15 for all analyses.

\section{Results}

Our analytic sample included 2,725 females aged $20-24$ years (population $\mathrm{N}=4,008,722$; Figure $1 ; 80.6 \%$ of total). The percentage of our sample reporting that they discussed specific sexuality education topics at school varied from $71.2 \%$ to 93.2\% (Figure 2). In our sample, 60.6\% received comprehensive sexuality education, $15.6 \%$ received incomplete sexuality education, and $23.9 \%$ did not receive any sexuality education (Table 1 ). When comparing receipt of sexuality education, our sample varied by wealth $(<.01)$, age at first sexual intercourse $(p=.04)$, and whether someone at home discussed sexuality education topics $(p<.01)$. There were no significant differences in religiousness, indigenous status, or rural residence by receipt of sexuality education (Table 1 ).

Nearly two thirds (62.5\%) of our sample reported using modern contraception at first sexual intercourse. Among those who used a modern method of contraception, the overwhelming majority reported using condoms (91.1\%); a minority reported using emergency contraceptive pills (3.8\%), contraceptive pills (2.7\%), and injections (1.4\%). The remaining methods had lower than $1 \%$ utilization.

In bivariate analysis, both comprehensive and incomplete sexuality education were positively associated with modern contraception use at first sexual intercourse $(p \leq .01)$. In multivariable analysis, the odds of using modern contraception at first sexual intercourse among women who had received comprehensive (odds ratio $=2.3 ; 95 \%$ confidence interval $[\mathrm{CI}]$ : $1.7-3.2$ ) and incomplete (odds ratio $=2.4 ; 95 \% \mathrm{CI}$ : $1.3-4.2$ ) sexuality education were similar and significantly larger compared with women who had not received any sexuality education (Table 2). Other factors associated with using modern contraception at first sex were urban residence, higher wealth, and older age at first sexual intercourse. Higher reported level of religiousness was not associated with use of modern contraception at first sexual intercourse.

When we performed multivariable predicted probabilities, holding all other covariates at the mean, women who reported receipt of comprehensive or incomplete sexuality education were $20 \%$ and $22 \%$ more likely to use modern contraception at first sexual intercourse, respectively, than those who did not receive any sexuality education $(p<.01)$. The absolute probabilities of using a modern method of contraception at first sexual intercourse by sexuality education group were $57.5 \%$ (95\% CI: $55.2 \%-59.8 \%$ ), $60.4 \%$ (95\% CI: 56.0\%-64.9\%), and 37.6\% (95\% CI: 33.9\%-41.3\%) among comprehensive, incomplete, and no sexuality education, respectively (Figure 3), controlling for all model covariates.

\section{Discussion}

In a nationally representative sample of young Mexican women, we observed a positive and significant independent association between receiving sexuality education at school and using modern contraception at first sexual intercourse. There are diverse plausible pathways to explain the relationship of sexuality education and modern contraception use at first sexual intercourse.

Our results indicate that accounting for differences in socioeconomic and cultural factors, the relationship between sexuality education and contraceptive use persisted. Young women who received either comprehensive or incomplete sexuality education as adolescents were about $20 \%$ more likely to use modern contraception at first sexual intercourse compared with those who did not receive any sexuality education.

Our sensitivity analyses varying the definition of incomplete sexuality education and comparing incomplete directly to comprehensive sexuality education showed that there was no 
Table 1

Sample characteristics by receipt of sex education among women who reported sexual intercourse, ENFaDEA 2017, Mexico

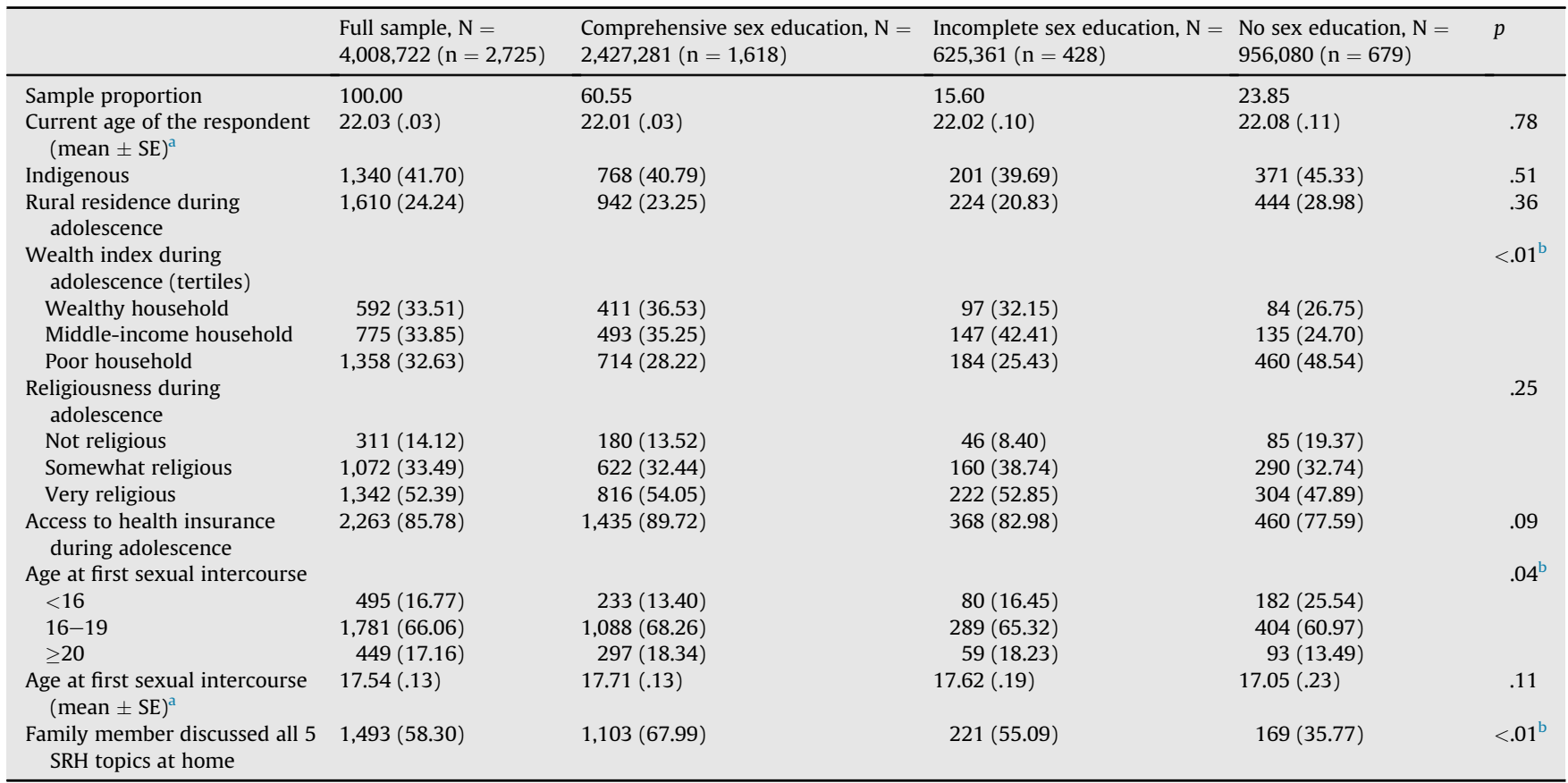

Unless otherwise marked, the $p$ values were calculated using chi-square test of proportions.

Counts are unweighted, and percentages, mean, and SE are weighted.

ENFaDEA = National Survey of the Determinant Factors of Adolescent Pregnancy; SE = standard error; SRH = sexual and reproductive health.

a The $p$ value was calculated using a t test.

b Significant at alpha $<.05$.

significant difference in the odds of using modern contraception at first sexual intercourse in any of these iterations. This is further reinforced by the similar effect size between comprehensive and incomplete sexuality education in the main model presented in this analysis. Although the number of topics covered during sexuality education varies widely, our results suggest no difference between incomplete and comprehensive sexuality education and modern contraceptive utilization among young Mexican women. As observed in the sociodemographic differences of the study sample by sexuality education group, the group that received no sexuality education is the most disadvantaged, with the highest proportion in the lowest wealth tertile and the youngest age group at first sexual intercourse. It is not that comprehensive sexuality education is not better than incomplete sexuality education, but rather receiving no sexuality education at all puts adolescents most at risk for not using contraception at first sexual intercourse.

The overwhelming majority of young women who used a method at first sexual intercourse reported using condoms, in this as in previous surveys [27]. When used correctly and consistently, condoms prevent pregnancy with the added benefit of preventing sexually transmitted infections; however, the typical use failure rate is much higher than perfect use, and adolescents are at even higher risk of incorrect or inconsistent use [28].

Our study aligns with prior studies in Mexico, indicating that comprehensive sexuality education receipt is associated with improved sexual health behaviors [16,25]. The Mexican National demographic survey (Spanish acronym: ENADID) has repeatedly found that the use of contraception at first sexual intercourse increases with increasing educational attainment, but ENADID does not contain information about receipt of school sexual education curricula [27]. Their results do show, however, in line with our results, that the proportion of women that used contraception at first sexual intercourse is higher among urban and nonindigenous women [27].

Previous work in Mexico has shown that adolescents often access contraceptives through pharmacies [27]; that when accessing family planning within the health services they report lower quality of care [29]; and that they are usually offered the most effective, long-acting reversible methods only after childbirth $[29,30]$. A small proportion of our sample reported use of emergency contraceptive pills, which is available over the counter even to adolescents: although long-lasting efforts to increase knowledge of this option in Mexico have been carried out, gaps in knowledge and use are still reported [31,32]. National goals to reduce adolescent fertility will require efforts to expand access to effective methods before sexual initiation and before a first pregnancy [3].

Mexico is a heavily Catholic country and many young women in our sample considered themselves very religious during adolescence, but religiosity was not significantly associated with use of modern contraception at first sex in our study. Evidence suggests that Mexican Catholics are not opposed to the use of contraception, that many feel that the Catholic Church should permit use of modern contraception, and that Catholic parents support school-based sexuality education [33] and adolescent access to contraception [34]. National surveys support this; religious beliefs are rarely cited as a reason for nonuse of contraception at first sexual intercourse [27].

This study has limitations. First, our analysis relied on selfreport data about events that occurred in the past; we do not 
Table 2

Multivariable analysis of the association between receiving sexuality education and modern contraception use at first sexual intercourse

\begin{tabular}{ll}
\hline & $\begin{array}{l}\text { Modern contraception use, } \\
\mathrm{N}=4,008,722(\mathrm{n}=2,725), \\
\mathrm{OR}(95 \% \mathrm{CI})\end{array}$ \\
\hline Received sexuality education & \\
$\quad$ None & 1.00 (referent) \\
Incomplete & $2.35(1.31,4.20)$ \\
Comprehensive & $2.32(1.68,3.20)$ \\
Location & \\
Urban & 1.00 (referent) \\
Rural & $.53(.39, .72)$ \\
Wealth index (tertiles) & \\
Rich household & $1.00($ referent $)$ \\
Middle-income household & $.48(.32, .72)$ \\
Poor household & $.34(.29, .40)$ \\
Access to health insurance at age 15 & \\
No & 1.00 (referent) \\
Yes & $1.56(.96,2.54)$ \\
Religiousness during adolescence & \\
Not religious & 1.00 (referent) \\
Somewhat religious & $.86(.39,1.89)$ \\
Very religious & $.90(.48,1.70)$ \\
Age at first sexual intercourse & \\
$<16$ & 1.00 (referent) \\
$16-19$ & $2.23(1.41,3.52)$ \\
$\geq 20$ & $2.91(1.73,4.88)$ \\
\hline
\end{tabular}

$\mathrm{CI}=$ confidence interval; $\mathrm{OR}=$ odds ratio.

know how accurately participants recalled or reported past events. However, the average age of participants is age 22, which is closer to the age at which first sexual intercourse occurred than other Mexican surveys that sample older adults about these same experiences [27]. Second, owing to the crosssectional study design, we cannot determine definitively whether receipt of sexuality education preceded use or nonuse of modern contraception at first sexual intercourse; although, since Mexico has a national policy of comprehensive sexuality education beginning from primary school, temporality is likely not an issue in this analysis. Furthermore, the survey did not differentiate specifically between formal and informal sexuality education, yet because of the national policy, we considered the provision of information by a professor or professional to capture formal sexuality education [15]. Next, the definition of Indigenous status used in ENFaDEA is different than the official government definition used in other population-based surveys [35], limiting our ability to compare this variable. In addition, although we were able to include a range of sociodemographic information associated with our exposure and outcome, unmeasured confounders may remain. Finally, we only assessed the association between sexuality education and modern contraception use at first sexual intercourse among women; therefore, we cannot comment on this association among men in Mexico.

Strengths of our study include a focus on a sample of women aged 20-24 years which provides a larger sample of young women and means less time had passed between events at the time they occurred and when they were surveyed than in other surveys [27]. The ENFaDEA also improves upon other crosssectional surveys by capturing key factors both at time of survey and at age 15 , which improves although does not solve temporality concerns.

Our study demonstrated that the probability of using modern contraception at first sexual intercourse is higher in young

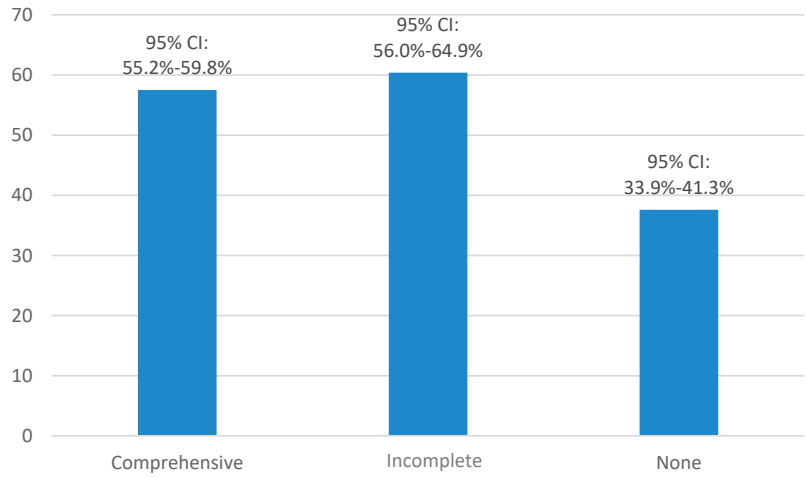

Figure 3. The predicted probabilities of using a modern method of contraception at first sexual intercourse by sexuality education group. $\mathrm{CI}=$ confidence interval.

Mexican women who received sexuality education than those who did not. While prior research has explored the association between sexuality education and contraception at first sexual intercourse in the U.S. [9-12], few studies have been conducted in Mexico [16,25]. Our analysis adds to the body of evidence on this topic, particularly for utilization in Latin America. These data should motivate increased support for the provision of comprehensive sexuality education in schools in Mexico.

\section{Acknowledgments}

The authors would like to thank the team of researchers and staff at the Escuela Nacional de Trabajo Social (ENTS)/National School of Social Work that designed and implemented ENFaDEA.

\section{Funding Sources}

Dr. Darney was supported by the Society of Family Planning Research Fund (SFPRF11-2) and grants R01HS025155 (Cottrell, PI) and K12HS022981 (Guise, PI) from the Agency for Healthcare Research and Quality.

\section{References}

[1] Sedgh G, Finer LB, Bankole A, et al. Adolescent pregnancy, birth, and abortion rates across countries: Levels and recent trends. J Adolesc Health 2015;56:223-30.

[2] Ganchimeg T, Ota E, Morisaki N, et al. Pregnancy and childbirth outcomes among adolescent mothers: A World Health Organization multicountry study. BJOG 2014;121:40-8.

[3] Estrategia Nacional para la Prevención del Embarazo en Adolescentes. Available at: https://www.gob.mx/inmujeres/acciones-y-programas/ estrategia-nacional-para-la-prevencion-del-embarazo-en-adolescentes-33 454. Accessed November 25, 2018.

[4] Santelli J, Sandfort T, Orr M. Transnational comparisons of adolescent contraceptive use: What can we learn from these comparisons? Arch Pediatr Adolesc Med 2008;162:92-4.

[5] Godeau E, Gabhainn SN, Vignes C, et al. Contraceptive use by 15-year-old students at their last sexual intercourse. Arch Pediatr Adolesc Med 2008; 162:66-73.

[6] Manlove J, Ikramullah E, Mincieli L, et al. Trends in sexual experience, contraceptive use, and teenage childbearing: 1992 - 2002. J Adolesc Health 2009;44: 413-23.

[7] Anderson JE, Santelli JS, Morrow B. Trends in adolescent contraceptive use, unprotected and poorly protected sex, 1991-2003. J Adolesc Health 2006;38: 734-9.

[8] Santelli JS, Abma J, Ventura S, et al. Can changes in sexual behaviors among high school students explain the decline in teen pregnancy rates in the 1990s? J Adolesc Health 2004;35:80-90. 
[9] Jaramillo N, Buhi ER, Elder JP, et al. Associations between sex education and contraceptive use among heterosexually active, adolescent males in the United States. J Adolesc Health 2017;60:534-40.

[10] Isley MM, Edelman A, Kaneshiro B, etal. Sex education and contraceptive use at coital debut in the United States: Results from cycle 6 of the national survey of family growth. Contraception 2010;82:236-42.

[11] Lindberg LD, Maddow-Zimet I. Consequences of sex education on teen and young adult sexual behaviors and outcomes. J Adolesc Health 2012:51: 332-8.

[12] Mueller TE, Gavin LE, Kulkarni A. The association between sex education and youth's engagement in sexual intercourse, age at first intercourse, and birth control use at first sex. J Adolesc Health 2008;42: 89-96.

[13] Kohler PK, Manhart LE, Lafferty WE. Abstinence-only and comprehensive sex education and the initiation of sexual activity and teen pregnancy. J Adolesc Health 2008;42:344-51.

[14] National Guidelines Task Force. Guidelines for comprehensive sexuality education: Kindergarten-12th grade. 3rd ed. Washington, DC: Sexuality Information and Education Council of the United States; 2004.

[15] Chandra-Mouli V, Gómez Garbero L, Plesons M, et al. Evolution and resistance to sexuality education in Mexico. Glob Health Sci Pract 2018;6:137-49.

[16] Rojas R, de Castro F, Villalobos A, et al. Educación sexual integral: Cobertura, homogeneidad, integralidad y continuidad en escuelas de México [Comprehensive sexual education in Mexico: An analysis of coverage, comprehensiveness and continuity of contents in Mexican public and private schools] Salud Publica Mex 2017;59:19-27.

[17] Encuesta Nacional de los Factores Determinantes del Embarazo Adolescente. Available at: http://www.trabajosocial.unam.mx/enfadea/. Accessed December 1, 2018.

[18] INEGI. Encuesta Nacional de la Dinámica Demográfica. Available at: https:// www.inegi.org.mx/programas/enadid/2014/. Accessed May 1, 2019.

[19] Encuesta Nacional de Opinión Católica. Available at: http://catolicasmexico. org/ns/. Accessed May 1, 2019.

[20] Family planning/contraception. Available at: http://www.who.int/news room/fact-sheets/detail/family-planning-contraception. Accessed November $25,2018$.

[21] DeVillis R. Factor analysis strategies. In: Scale Development: Theory and Applications. Newbery Park, CA: Sage Publications; 1991.

[22] Pearce LD, Hayward GM, Pearlman JA. Measuring five dimensions of religiosity across adolescence. Rev Relig Res 2017;59:367-93.

[23] Mcandrew S, Voas D. Measuring religiosity using surveys. SQB Topic Overview 2011:4:1-15.
[24] Bartkowski JP, Ramos-Wada AI, Ellison CG, et al. Faith, race-ethnicity, and public policy preferences: Religious schemas and abortion attitudes among US Latinos. J Sci Study Relig 2012;51:343-58.

[25] de Castro F, Rojas-Martínez R, Villalobos-Hernández A et al. Sexual and reproductive health outcomes are positively associated with comprehensive sexual education exposure in Mexican high-school students. PLoS One $2018 ; 13: 1-15$

[26] King G, Tomz M, Wittenberg J. Making the most of statistical analyses: Improving interpretation and presentation. Am J Pol Sci 2000; 44:347-61.

[27] National Survey of Demographic Dynamics (ENADID). Reasons for not using contraception at first sexual intercourse. Aguascalientes, México: Instituto Nacional de Estadística, Geografía e Informática (INEGI); 2014. Available at: https://www.inegi.org.mx/programas/enadid/2014/. Accessed December 1, 2018.

[28] Kost K, Singh S, Vaughan B, et al. Estimates of contraceptive failure from the 2002 national survey of family growth. Contraception 2008; 77:10-21.

[29] Darney BG, Saavedra-Avendano B, Sosa-Rubi SG, et al. Comparison of family-planning service quality reported by adolescents and young adult women in Mexico. Int J Gynecol Obstet 2016;134:22-8.

[30] Saavedra-Avendano B, Andrade-Romo Z, Rodriguez MI, et al. Adoles cents and long-acting reversible contraception: Lessons from Mexico. Matern Child Health J 2017;21:1724-33.

[31] Han L, Saavedra-Avendano B, Lambert W, et al. Emergency contraception in Mexico: Trends in knowledge and ever-use 2006-2014. Matern Child Health J 2017;21:2132-9.

[32] Heimburger A, Acevedo-Garcia D, Schiavon R, et al. Emergency contraception in Mexico City: Knowledge, attitudes, and practices among providers and potential clients after a 3-year introduction effort. Contraception 2002;66:321-9.

[33] 2014 National Catholic Opinion survey. Available at: https:// catolicasmexico.org/ns/. Accessed November 25, 2018.

[34] Kung S, Saavedra B, Aldaz Vélez E, et al. Religiosity and support for adolescent access to contraception among Mexican catholic parents (oral). In: Presented as Paper at Population Association of America Annual Meeting. Austin, TX: Population Association of America; April $11-13,2019$.

[35] Comision Nacional para el Desarrollo de los Pueblos Indigenas, Indicadores y estadísticas. 2012. Available at: http://www.cdi.gob.mx/index.\% OD\%0Aphp? option=com_content\&view =category\&id=38\&Itemid $=54 \% 0$ D\%0A. Accessed June 1, 2012. 